Delle Monache, F.; Pizzolatti, M.G.; Yunes, R.A. Three xanthones from P. cyparissias. Phytochemistry, v. 48, n. 4, p. 725-728, 1998.

${ }^{13}$ Pizzolatti, M.G.; Luciano, C.; Delle Monache, F. Styryl-pyrones from Polygala sabulosa. Phytochemistry, v. 55, n. 7, p. 819$822,2000$.

${ }^{14}$ Zani, C.L.; Chaves, P.P.G.; Queiroz, R.; Oliveira, A.B.; Cardoso, J. E.; Anjos, A.M.G.; Grandi, T.S.M. Brine shrimp lethality assay as a prescreening system for anti- Trypanosoma cruzy activity. Phytomedicine, v. 2, n. 1, p. 47-50, 1995.

${ }^{15}$ Finney, D.J. Probit Analysis. 3. ed. Cambridge: Cambridge University Press, p. 76-80, 1971.

*Autor para correspondência:

Profa. Inês Maria Costa Brighente

Departamento de Química - CFM

Universidade Federal de Santa Catarina

Campus Universitário - Trindade

88040-900 Florianópolis - SC Brasil

E-mail: ines@qmc.ufsc.br ou ines@linhalivre.net

Telefone: (48) 331-9219 - Fax: (48) 331-9711

\section{Morfo-anatomia das folhas de Vernonia condensata Baker (Asteraceae), o "figatil"}

\author{
Lolis, M.I.G.A. ; Milaneze-Gutierre, M.A.*
}

Departamento de Biologia, Universidade Estadual de Maringá, Paraná, Brasil

\section{Resumo}

As folhas de Vernonia condensata Baker, popularmente denominada de figatil foram analisadas morfoanatomicamente com objetivo de fornecer subsídios à farmacognosia. As folhas são ovaladas, de ápice agudo, base atenuada, bordo serrilhado, hipoestomáticas com estômatos do tipo anomocítico e dois tipos de tricomas glandulares. O mesofilo é dorsiventral e os feixes vasculares são colaterais. Ocorrem drusas no pecíolo.

\begin{abstract}
The leaves of Vernonia condensata Baker, popularly known as figatil were analyzed in its morphology and anatomy with the aim to provide information to pharmacological studies. The leaves are ovate with acute apex, atenuate base, serriate margin and hypostamatic anomocytic stomata and two types of glandular trichomes. The mesophyll is dorsiventral and the vascular bundles are colateral. Druses occur in the petiole.
\end{abstract}

As populações humanas utilizam diversas espécies vegetais em busca da cura para as mais variadas moléstias. Tal procedimento é muito difundido, não só em nosso país como em todo o mundo, sedimentando-se ao longo do tempo, como resultado do acúmulo de conhecimentos sobre as plantas por diversos grupos étnicos ${ }^{1}$.

A família Asteraceae é cosmopolita, estando mais bem representada nas regiões temperadas e subtropicais, contando com aproximadamente 1.100 gêneros e 19.000 espécies² $^{2}$.

Como verificado em Silva ${ }^{3}$, Freire e Estrella ${ }^{4}$, muitas espécies de Asteraceae são utilizadas como plantas medicinais, com variadas indicações terapêuticas, preparos e utilizações. As folhas de Vernonia condensata (figura 1), popularmente designada de figatil, são utilizadas na preparação de infusões, ou então maceradas para preparação de "sumos". Estes são analgésicos e colagogos, usados para o tratamento de cefaléias de origem digestiva, possuindo ainda, ação citoprotetora da mucosa gastrintestinal ${ }^{3}$. Muitas das espécies utilizadas como medicinais são comercializadas secas, em fragmentos de dimensões variadas e portanto, sua adulteração torna-se facilitada. Para a avaliação da qualidade dos lotes de drogas, a microscopia costuma ser considerada o método mais rápido, fácil e barato na identificação e verificação da pureza de drogas vegetais $^{5}$, e caso a droga estiver moída ou rasurada, certos elementos como cristais, estômatos e pêlos podem ser identificados por esta análise ${ }^{6}$. No Brasil, embora existam normas que garantam a qualidade dos fitoterápicos, estas nem sempre 
são cumpridas, podendo gerar fraude nos produtos ao serem comercializados misturados, propositadamente ou não, com outras espécies vegetais ${ }^{3}$. Este fato justifica a necessidade de estudos que caracterizem morfo-anatomicamente os órgãos vegetais e conseqüentemente, as drogas deles derivadas.

As folhas de V. condensata são alternas, levemente coriáceas, pecioladas, não latescentes, simples, de limbo inteiro, ovalado, ápice agudo, base atenuada e bordo serrilhado. A nervação mostra-se com padrão camptódromo-broquidódromo, no qual as nervuras secundárias são uniformemente curvadas, terminando em arcos e unindo-se às subjacentes por ângulos que variaram de quase reto a agudo. A arquitetura foliar, a qual inclui o padrão de nervação, mostra-se como uma importante ferramenta para a farmacognosia, devendo ser mais bem explorada neste tipo de análise.

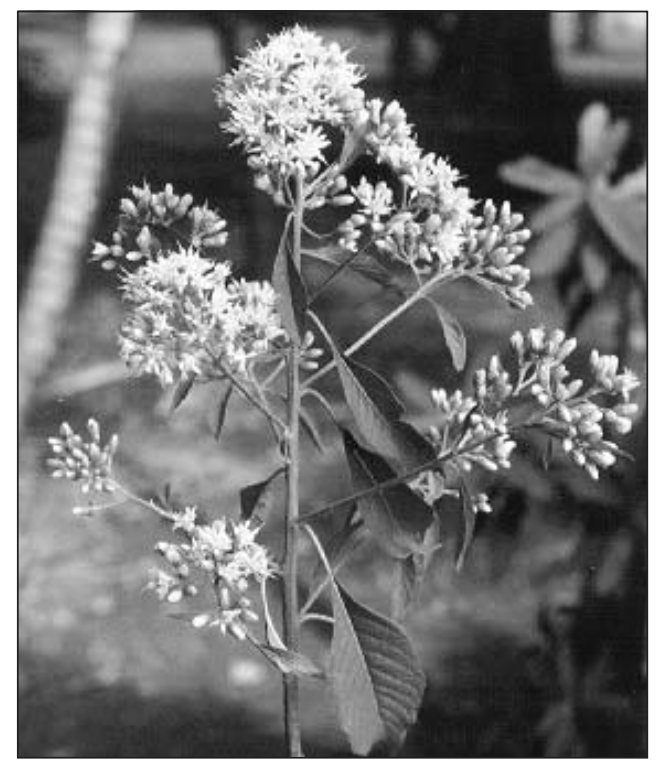

Figura 1. Ramo reprodutivo de Vernonia condensata.

Nas folhas de $V$. condensata as células da face adaxial possuem contorno plano, enquanto que as da face abaxial mostraram contorno sinuoso (figura 2 - A e B), ocorrendo estômatos anomocíticos apenas na face abaxial. Folhas hipoestomáticas foram encontradas também em Vernonia polyanthes ${ }^{7}$ e em Calea pinnatifida, Mikania hirsutissima e M. glomerata ${ }^{5}$. Metcalfe e $\mathrm{Chalk}^{8}$ consideram comuns nesta família a ocorrência de estômatos anomocíticos.

Como anexos epidérmicos ocorrem dois tipos de tricomas glandulares, embora mais esparsos na face adaxial. Um destes tricomas mostra-se com pedúnculo formado por duas pequenas células, dando-lhe aparência séssil, e com a cabeça arredondada, glandular, constituída por duas células (figura 2 C). O outro tipo de tricoma possui uma grande célula apical, conferindo-lhe o formato de um biruta (figura 2 - D), a qual se destaca com facilidade durante o processo de preparação das lâminas histológicas. Esta característica, mais que os tipos estomáticos, mostra-se relevante nas análises farmacognósticas, visto que os tricomas das Asteraceae são morfologicamente muito variados, amplamente distribuídos entre as espécies, podendo ser glandulares ou não ${ }^{8}$.
O mesofilo desta espécie é dorsiventral, cujo parênquima paliçádico possui de duas a três camadas celulares na região mediana da folha (Figura 3 - A), uma a duas na base e no ápice e apenas uma camada celular no bordo mediano. $\mathrm{O}$ parênquima lacunoso esteve composto por três a cinco camadas de células. Este tipo de mesofilo também ocorre em outras espécies de Asteraceae ${ }^{7,9,10}$.

A nervura central apresenta três grandes feixes vasculares colaterais na porção mediana do limbo (figura 3 - B), enquanto que na base foliar ocorreram cinco destes feixes, como também verificado na região mediana do pecíolo, sendo um deles mais desenvolvido que os demais. Nesta porção foliar foram observadas drusas finamente espiculadas.

Na nervura central das folhas de $V$. condensata estão várias camadas de colênquima angular (figura 3 - C). Tanto este tipo de tecido de sustentação quanto a disposição dos tecidos condutores são comuns a outros membros desta família ${ }^{8}$.
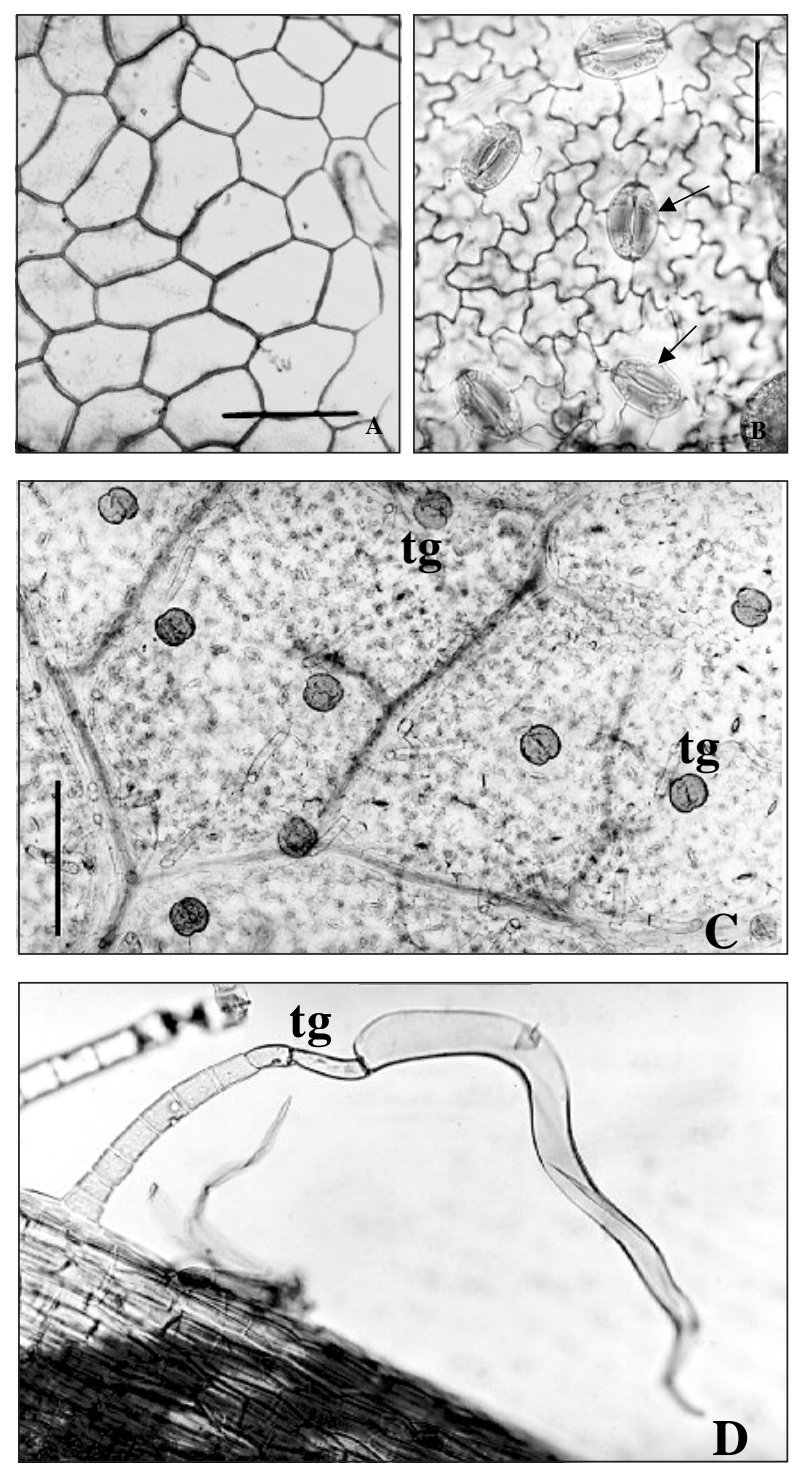

Figura 2. Epiderme adaxial (A) e abaxial (B) de Vernonia condensata. Em D e E: os dois tipos de tricomas glandulares presentes. Barras de A, B e D: 50mm, C: 200mm. As setas indicam estômatos e tg: tricomas. 

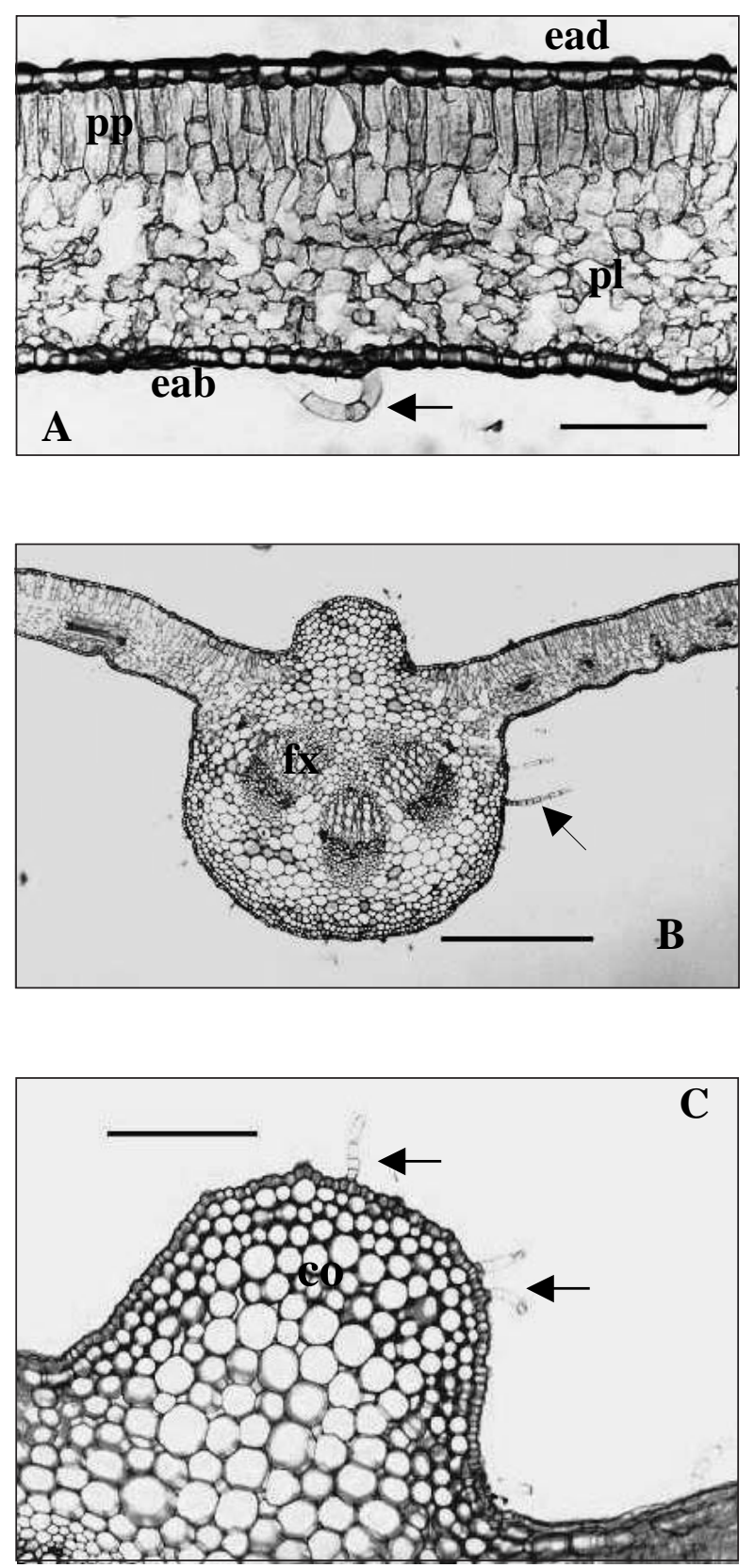

Figura 3. Cortes transversais medianos das folhas de Vernonia condensata. Em A: região do limbo, e B: região da nervura central. C: colênquima (co) na nervura central. ead: epiderme adaxial, eab: epiderme abaxial, fx: feixe vascular, pp: parênquima paliçádico, pl: parênquima lacunoso, @: tricomas. Barra de A: $100 \mathrm{~mm}, \mathrm{~B}: 500 \mathrm{~mm} \mathrm{e} \mathrm{C:} 200 \mathrm{~mm}$.

As características morfo-anatômicas acima apontadas servem como subsídios para diferenciar as folhas de $V$. condensata de muitas outras espécies. Entretanto, a ocorrência de diversas estruturas em comum com outras de sua família, ressalta a necessidade de ampliar os estudos desta natureza, neste amplo e diversificado grupamento vegetal.

\section{Material e Métodos}

Neste estudo foram utilizadas folhas maduras de Vernonia condensata Baker cultivadas no Horto Didático de
Plantas Medicinais "Professora Irenice Silva", situado no Campus da Universidade Estadual de Maringá.

O estudo morfológico das folhas foi realizado segundo Radford $^{11}$ e a análise da distribuição das nervuras foliares segundo Hickey ${ }^{12}$. Para tanto, folhas foram diafanizadas segundo a técnica proposta por Handro ${ }^{13}$, mas modificada pelo uso de safranina alcoólica $1 \%$ em etanol $70 \%$.

Para a análise anatômica, as folhas foram fixadas em FAA $50 \%$ e a seguir emblocadas em parafina ${ }^{14}$. As secções anatômicas foram coradas com safrablau ${ }^{15}$. Este corante também foi utilizado nas epidermes destacadas de folhas frescas com auxilio de pinça e lâmina de barbear.

\section{Referências}

${ }^{1}$ Albiero, A.L.M. Estudo farmacognóstico de Sapindus saponaria L. (sabão de soldado). São Paulo: Dissertação de Mestrado, Universidade de São Paulo. 1994.

${ }^{2}$ Cronquist, A. The classification of flowering plants. New York: New York Botanical Garden, 555p., 1988.

${ }^{3}$ Silva, I. et al. Noções sobre o organismo humano e utilização de plantas medicinais. Cascavel: Assoeste, 1995.

${ }^{4}$ Freire, S.; Estrella, U. Medicinal Compositae of the Pampean biogeographic province: key for the identification of taxa and illustrations. Part II. Compositae with isomorphic florets and capillary bristles pappus (group 3). Acta Farmaceutica Bonaerense, v. 18, n. 4, p. 283-294, 1999.

${ }^{5}$ Oliveira, F.; Akisue, G.; Akisue, M.K. Farmacognosia. São Paulo: Atheneu, 412p., 1991.

${ }^{6}$ Bacchi, E.M. Controle de qualidade de fitoterápicos. In: Di Stasi, L.C. (Org.). Plantas medicinais: arte e ciência. Um guia de estudos interdisciplinares. São Paulo: Editora UNESP, p. 169-186, 1996.

${ }^{7}$ Scatena, V.L. Estudo morfo-anatômico de plântulas e de órgãos vegetativos aéreos e ensaio farmacológico de Vernonia polyanthes Less. (Compositae). Rio Claro, 64p. Dissertação de Mestrado, Instituto de Biociências, Universidade Estadual Paulista, 1983.

${ }^{8}$ Metcalfe, C.R.; Chalk, L. Asteraceae. In: Anatomy of the dicotyledons. Oxford: Claredon Press, 2. ed., v. 1, p. 620-631, 1972.

${ }^{9}$ Duarte, M.R., Estelita, M.E.M. Anatomical characters of Bidens pilosa L. Asteraceae. Hoehnea, v. 26, n. 1, p. 15-27, 1999.

${ }^{10}$ Tavares, E.S.; Gil, V.R.; Viana, V.R.C. Anatomia do eixo vegetativo de Ageratum conyzoides L. (Asteraceae). Revista Brasileira de Farmácia, v. 81, n. 1/2, p. 25-28, 2000.

${ }^{11}$ Radford, A. Fundamentals of plant systematics. New York: Harper \& How Publishers, 498p., 1986.

${ }^{12}$ Hickey, L.J. A revised classification of the architecture of dicotyledonous leaves. In: Metcalfe, C.R., Chalk, L. Anatomy of the dicotiledons - Systematic anatomy of leaf and stem with a brief history of the subject. Claredon Press, Oxford, 2. ed., v. $1,1979$.

${ }^{13}$ Handro, W. Contribuição ao estudo da venação e anatomia foliar das amarantáceas dos cerrados. Anais da Academia Brasileira de Ciências, v. 36, n. 4, p. 479-499, 1964.

${ }^{14}$ Johansen, D.A. Plant microtechnique. New York, McGraw- 
Hill Book Company, 1940.

${ }^{15}$ Kraus, J.; Arduin, M. Manual básico de métodos em morfologia vegetal. EDUR, Seropédica, RJ, 1997.

*Autor para correspondência:

Profa. Dra. Maria Auxiliadora Milaneze Gutierre

Universidade Estadual de Maringá

Departamento de Biologia

Av. Colombo, n. 5790 - CEP 87020-900 - Maringá - PR

E-mail:milaneze@uem.br
Otimização do processo de extração de própolis através da verificação da atividade antimicrobiana

\author{
Dos Santos, C.R.; Arcenio, F., Carvalho, E.S.; Lúcio, E.M.R.A., \\ Araújo, G.L.; Teixeira, L.A.; Sharapin, N.; Rocha, L.*
}

Laboratório de Tecnologia de Produtos Naturais, Faculdade de Farmácia, Universidade Federal Fluminense.

\section{Resumo}

A própolis, também conhecida como "cola de abelhas" possui atividade antimicrobiana, antiinflamatória, anestésica e imunoestimulante. Amostras de diferentes origens geográficas podem apresentar composição química bem diferente, porém continuam sendo responsáveis por atividade antibacteriana, inclusive contra cepas multirresistentes de Staphylococcus aureus. Este trabalho teve por objetivo otimizar o processo de extração visando determinar a melhor alcoolatura para a obtenção de tinturas de própolis com maior atividade antimicrobiana. Amostras de própolis foram extraídas com diferentes misturas hidroalcoólicas, variando o teor de etanol entre $90 \%$ a água pura, obtendo assim 11 tinturas diferentes. Todas as tinturas foram aplicadas em discos de papel, secos e colocados sobre a superfície de placas contendo ágar inoculado com cepa multirresistente de $S$. aureus. As placas foram incubadas e avaliadas no dia seguinte quanto à presença de halos de inibição. Os melhores resultados foram obtidos com extratos contendo 50 a $90 \%$ de etanol. O trabalho sugere a utilização da alcoolatura de $70 \%$ como a ideal para a obtenção de tinturas de própolis.

\begin{abstract}
Bee glue (propolis) possesses antimicrobial, antiinflammatory, anaesthetic and immunostimulating activities. Propolis composition is extraordinary variable; samples from different geographic origin may posse's entirely different chemical composition. In different propolis samples, various substance combinations are responsible for the antibacterial activity of the bee glue. The aim of the study was to evaluate the best ethanolic extract concentration using Staphylococcus aureus multiresistant. Ethanol extracts from different concentration (10 to 90\%) were applied on paper disks, dried, and put on the surface of nutrient agar plates with the overlay containing $S$. aureus. The plates were then incubated and evaluated the next day for the presence of inhibition zones. The best result was verified among 60 to $90 \%$ of ethanolic extract of propolis. This paper suggests the use of the alcool $70 \%$ as the ideal for the extration of propolis.
\end{abstract}

Própolis, conhecida como "cola das abelhas"1, é o produto final de uma mistura de gomas, resinas e bálsamos de diversas fontes vegetais, coletados e processados por abelhas 